\title{
- Tendências de modernização do setor lácteo: monitoramento da qualidade do leite pela contagem de células somáticas
}

\section{Modernization trends in the dairy industry: milk quality monitoring by somatic cell counts}

\author{
Hélio Langoni - CRMV-SP $n^{0} 1912$ \\ Professor Adjunto da Disciplina de Zoonoses - FMVZ - UNESP
}

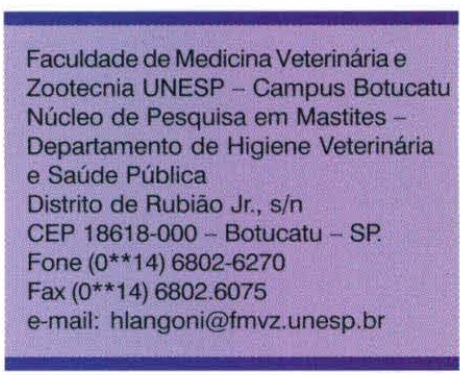

\section{RESUMO}

A mastite bovina é a principal afecção dos animais produtores de leite, que causa grandes prejuízos à indústria de laticínios. Sua etiologia é múltipla, o que dificulta sua profilaxia. O presente trabalho reflete a importância do seu controle e discute aspectos da contagem de células somáticas no monitoramento da saúde da glândula mamária, visando a obtenção de leite de melhor qualidade, com menor risco de infecção a seus consumidores, uma vez que tanto o leite como seus derivados podem veicular agentes causadores de zoonoses.

Palavras-chave: mastites, células somáticas, tendências, monitoramento.

\section{Introdução}

$A$ s mastites constituem-se na principal afecção dos animais destinados à produção leiteira; caracterizam-se por alterações físicas, químicas e bacteriológicas do leite, bem como do tecido glandular mamário. São consideradas como um fator de grande impacto na pecuária leiteira mundial, levando-se em consideração as perdas econômicas ocasionadas pela redução da produção e pelas alterações dos componentes lácteos comprometendo a qualidade de seus derivados.

Ressaltam-se, ainda, os aspectos econômicos relevantes: honorários profissionais, custos com medicamentos e descarte precoce de animais (NMC, 1996), bem como os aspectos de saúde pública, podendo colocar em risco a saúde do consumidor por veicular agentes causadores de graves zoonoses (LANGONI, et al., 1997a, b) e também de toxiinfecções alimentares.
São causadas por inúmeros microrganismos (LANGONI, et al., 1999), havendo a citação na literatura de 137 agentes envolvidos em sua etiologia (WATTS, 1998), incluindo-se bactérias, fungos, algas e vírus; entretanto, as mastites de origem bacteriana são as mais freqüentes (COSTA, et al., 1995, LANGONI et al., 1998) e, entre os agentes etiológicos que as causam, em ordem de importância estão os estafilococos, estreptococos e corinebactérias. Cerca de $50 \%$ das vacas em rebanhos nos quais não se praticam medidas de controle encontram-se infectadas (NMC, 1996). No Brasil a sua incidência também é alarmante, acometendo até $71 \%$ das vacas em rebanhos de Minas Gerais e São Paulo (COSTA et al., 1999), o que contribui, entre outros fatores, para que o Brasil continue sendo um país importador de leite, quando teria condições de inverter esta situação, pelo rebanho leiteiro que possui.

O Brasil ocupa a sexta posição no "ranking" entre os países produtores de leite, com 20,08 bilhões de litros, 
LANGONI, H. Tendências de modernização do setor lácteo: monitoramento da qualidade do leite pela contagem de células somáticas / Modernization trends in the dairy industry: milk quality monitoring by somatic cell counts. / Rev. educ. contin. CRMV-SP / Continuous Education Journal CRMV-SP, São Paulo, volume 3, fascículo 3, p. 57 - 64, 2000.

e vem apresentando taxas de crescimento, pelo aumento da demanda interna, entretanto, ainda, insuficientes para suprir o mercado interno, fazendo com que cresça o volume de importações de produtos lácteos (JANK, et al., 1999). Estima-se que a produção brasileira de leite relacione-se a 19.000 .000 de vacas, em sua maioria mestiças, não especializadas, de propriedade de pequenos produtores, com média de 50 1/produtor/dia, caracterizando-se uma baixa produtividade de 1,167 1/vaca/ano, com baixa qualidade do produto final (LARANJA-DA-FONSECA, 1997).

A Organização Mundial de Saúde (OMS) recomenda um consumo médio per capita de 216 litros de leite por ano; entretanto, o consumo brasileiro no ano de 1999 foi de somente 139 l/ano/pessoa (JANK et al., 1999), o que está bem abaixo daquele preconizado pela OMS e também quando comparado aos consumos da Argentina e Uruguai, que foram para o mesmo ano, de 190 1/ano e 238 1/ano, respectivamente (PARANÁ, 1999). Embora tenha ocorrido um aumento do consumo per capita no Brasil, este ainda está longe de alcançar o ideal, e, para tanto, deverão ser envidados esforços por parte de produtores, das indústrias, de instituições governamentais e de pesquisa.

Nesse sentido, o Ministério da Agricultura propôs legislação pertinente para a modernização do setor lácteo no Brasil, que se refere à melhor qualidade do leite, a partir de 2002, nas regiões Sul, Sudeste e Centro-Oeste, e, a partir de 2004, nas regiões Norte e Nordeste. Em linhas gerais, pretende-se implantar as contagens de células somáticas (CCS) como indicativo da sanidade de glândula mamária e parâmetro legal da qualidade do leite cru resfriado, comercializado em todo o país, com limites de 1 milhão, 750 mil e 400 mil células somáticas por $\mathrm{ml} /$ de leite, respectivamente, a partir de julho de 2002, julho de 2005 e janeiro de 2008, inicialmente para as regiões Sul, Sudeste e Centro-Oeste do País (BRASIL, 1999). Os limites legais praticados há mais de dez anos por diversos países são: 750.000 (Estados Unidos), 500.000 (Canadá), 400.000 (União Européia).

As condições de mercado e a aplicação das novas normas permitirão o conhecimento da situação do setor leiteiro no país, pela análise das informações do sistema agro-industrial do leite (RIBAS, 1998) e de sua cadeia produtiva. É claro que, para se atingir as metas propostas pelo Ministério da Agricultura, deverão ocorrer mudanças e, entre estas, uma maior especialização do produtor e a adequação da cadeia produtiva do leite às normas propostas.

\section{Células somáticas}

São primariamente os leucócitos do sangue, incluindo-se monócitos, linfócitos e neutrofilos, e ainda os macrófagos e células de descamação do epitélio glandular secretor. Essas células apresentam duas funções, quais sejam: combater os microrganimos nas infecções intramamárias e auxiliar na reparação dos tecidos secretores do leite, lesados pelo processo infeccioso e, conseqüente, inflamados (PHILPOT, 1998). Na glândula mamária normal, as células epiteliais perfazem 65 a $70 \%$ do total de células somáticas, mas, com a irritação da teta afetada, o número de leucócitos, principalmente os neutrófilos, aumentam drasticamente, como mecanismo de defesa que é muito efetivo no controle da mastite. Dos leucócitos que se acumulam na glândula mamária, como resposta inflamatória ao processo infeccioso, $46,0 \%$ a 64,0\% são polimorfonucleares (OTERO e CRUZ, 1992).

A contagem de células somáticas (CCS) é amplamente aceita como método clássico para monitorar o estado de saúde da glândula mamária (ERSKINE e BARTLETT, 1993) e adequada para utilização em programas de gerenciamento da qualidade do leite produzido é oferecido para consumo. Oxalá, seja realmente colocado em prática dentro da nossa realidade e inserido no Programa Nacional de Melhoria de Qualidade do Leite (PNMQL), como proposta de modernização do setor lácteo, como referido anteriormente, pois no Brasil somente 3\% das vacas leiteiras são submetidas ao controle oficial (RIBAS, 1998).

Nas mastites subclínicas, apesar de não ser possível diagnosticá-las visualmente, há um aumento acentuado de leucócitos polimorfonucleares, que possibilita a detecção dessa afecção por métodos indiretos, como a CCS. HARMON (1998a) reforça a importância da utilização desse método como medida padrão e ressalta que esta já está sendo assim utilizada em países em desenvolvimento, para se inferir sobre a qualidade do leite, por refletir a incidência de mastites subclínicas, que representam 90 a 95\% da doença (BLOOD e RADOSTISTIS, 1991). Levando-se em consideração os aspectos citológicos do leite mastítico, a mastite pode ser definida como uma enfermidade caracterizada pelo influxo de neutrófilos polimorfonucleares do tecido mamário para o leite da glândula acometida (HARMON, 1994).

De acordo com características dos patógenos envolvidos nas mastites, elas podem ser classificadas em contagiosas e ambientais (BRAMLEY et al., 1996). As do tipo contagioso referem-se às causadas por Staphylococcus aureus, Streptococcus agalactiae e Corynebacterium bovis, cujo habitat preferencial é o interior da glân- 


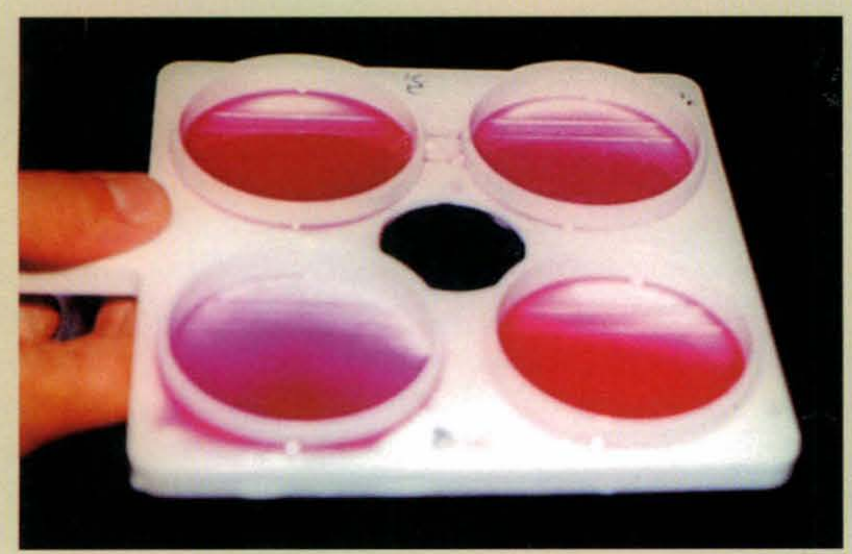

Figura 1. Reação +++ ao CMT. Observar cor violácea e viscosidade no receptáculo inferior esquerdo.

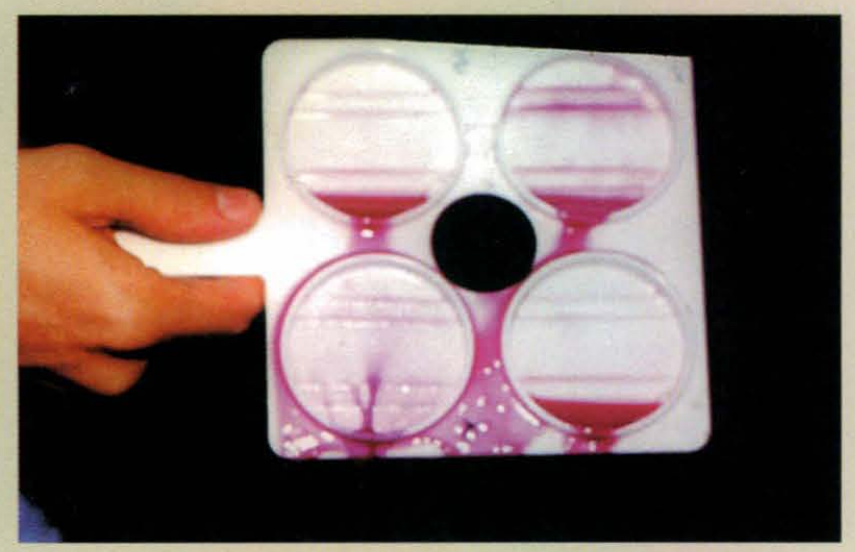

Figura 2. Reação +++ ao CMT. Observar gelificação, com aderência ao receptáculo inferior esquerdo. dula mamária. Estão associadas às expressivas elevações da CCS, com maior ocorrência de casos subclínicos, geralmente crônicos e de longa duração. O seu controle é mais fácil pela adoção de medidas higiênicas durante o processo de ordenha, especialmente quando se trata do Streptococcus agalactiae.

Quanto às ambientais, os agentes partilham do mesmo ecossistema da vaca, como o solo, piso, cama, esterco e materiais orgânicos. Entre eles, sobressaem a Escherichia coli, Enterobacter sp, Klebsiella sp, Pseudomonas sp, Staphylococcus sp coagulase-negativos, Streptococcus uberis e Streptococcus dysgalactiae, fungos e algas, entre outros. Apresentam-se com maior freqüência na forma clínica e não estão associadas a grandes elevações da CCS. A sua transmissão, embora possa acontecer durante o processo de ordenha, mormente por falhas no funcionamento do equipamento, ocorre principalmente entre ordenhas. Estes casos são de difícil controle, pois os seus principais agentes estão disseminados no meio ambiente onde os animais são explorados.

Os microrganismos mais comuns nas infecções intramamárias podem ser ainda divididos em patógenos maiores e menores. Os patógenos maiores provocam maior aumento na CCS e incluem o Staphylococcus aureus, e Streptococcus agalactiae e os coliformes. Os patógenos menores como Corynebacterium bovis, Staphylococcus coagulase-negativos e Micrococcus sp, normalmente duplicam ou triplicam a CCS quando se compara os quartos infectados aos não infectados (HARMON e LANGLOIS, 1986).

A contagem de células somáticas do rebanho e do tanque de expansão deve ser vista como ferramenta extremamente valiosa e que, entre outras finalidades, pode-se citar: o monitoramento da prevalência de mastite subclínica no rebanho, especialmente aquelas causadas por microganismos contagiosos, denotativo da qualidade do leite cru para a indústria, e indicação das condições higiênicas sob as quais o leite foi produzido nas propriedades (PHILPOT, 1998). Podem ser apontadas ainda: a possibilidade de estimativas das perdas da produção de leite, a orientação do produtor para tomada de decisões a fim de prevenir a transmissão da doença durante a lactação e a identificação de vacas para tratamento, secagem e descarte.

\section{Métodos de contagem de células somáticas}

São vários os métodos que podem ser utilizados na CCS, como: a contagem microscópica direta em lâminas, a contagem eletrônica de células (Coulter Count, Fossomatic), o California Mastitis Test - CMT e o Wisconsin Mastitis Test (WMT).

A contagem microscópica direta desenvolvida por PRESCOTT e BREED (1910), além de permitir distinguir os tipos celulares presentes nas amostras de leite, possibilita a visualização do microrganismo. Como aspecto negativo, ressalta-se-lhe a pouca praticidade, principalmente quando o número de amostras a ser analisado for grande, o que ocorre quando se trabalha com monitoramento de rebanhos.

O CMT, desenvolvido por SCHALM e NOORLANDER (1957), é um método de fácil execução, prático, utilizado mundialmente e de baixo custo. Ele é eficiente para se estimar o número de células somáticas presentes por $\mathrm{ml} / \mathrm{de}$ leite, correlacionando-se ainda à concentração de polimorfonucleares com o grau de positividade do referido teste, como mostra a Tabela 1, segundo RADOSTITS et al. (1994). 
LANGONI, H. Tendências de modernização do setor lácteo: monitoramento da qualidade do leite pela contagem de células somáticas / Modernization trends in the dairy industry: milk quality monitoring by somatic cell counts. / Rev. educ. contin. CRMV-SP / Continuous Education Journal CRMV-SP, São Paulo, volume 3, fascículo 3, p. $57-64,2000$.

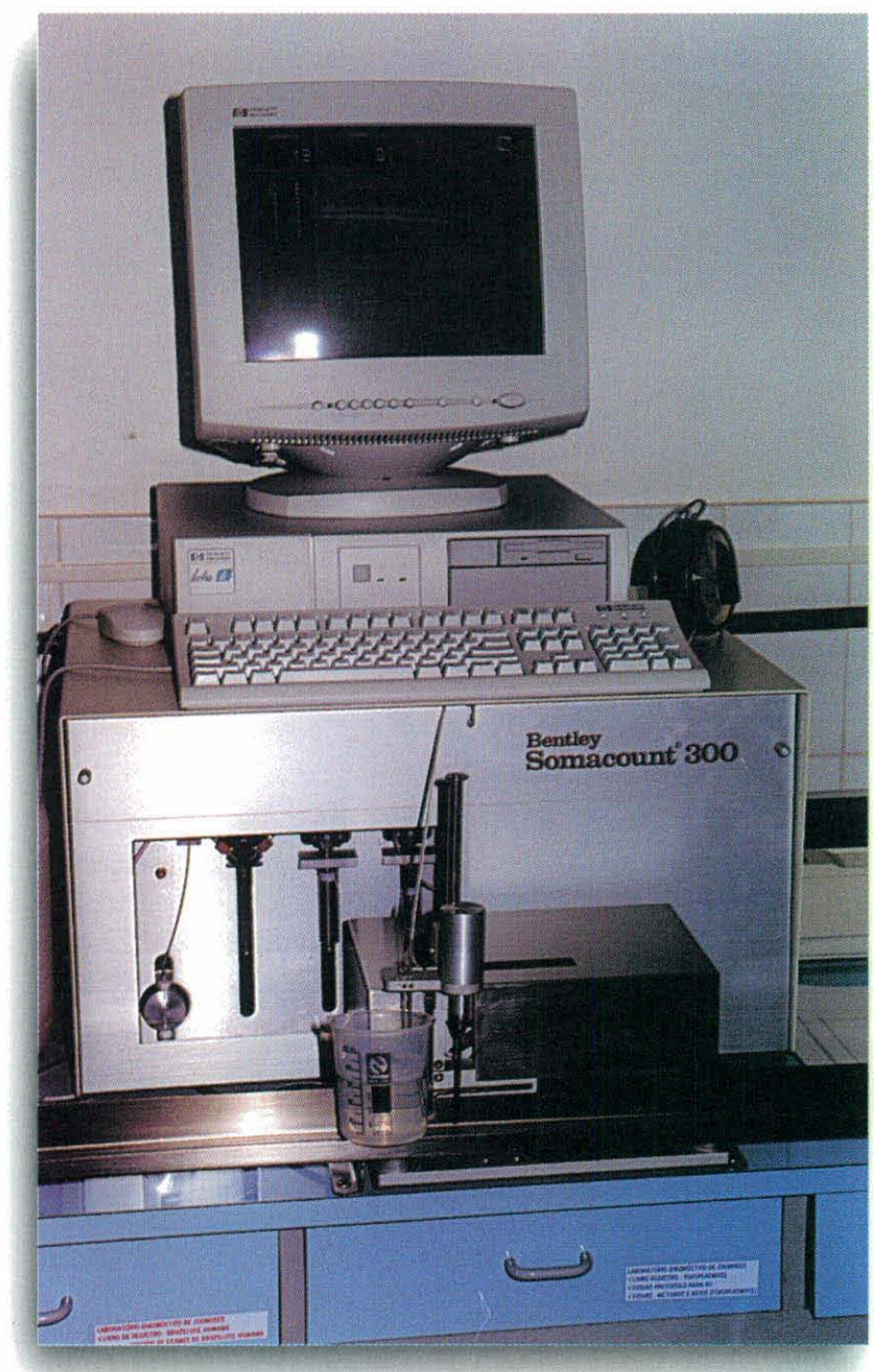

Figura 3. Aparelho para Contagem de Células Somáticas modelo Somacount 300. NUPEMAS, FMVZ, Botucatu, SP.

Entre as outras vantagens já assinaladas, o CMT pode ser realizado em cada quarto mamário individualmente, com uma bandeja ou raquete apropriada. Utiliza-se como reagente um detergente aniônico neutro, que atua rompendo a membrana das células presentes na amostra, liberando-se assim o conteúdo nucléico que apresenta maior viscosidade. $\mathrm{O}$ resultado do teste, portanto, é avaliado em função do grau de gelatinização ou viscosidade (Figuras 1 e 2), em cinco categorias: negativo, suspeito, +, ++ e +++. Apresenta como desvantagem a possibilidade de erros quanto às dosagens do reagente e do leite, que é de $2 \mathrm{ml}$ para cada um deles. Deve-se considerar, ainda, a necessidade de padronização da leitura, que está sujeita a variações, de acordo com quem realiza o teste. Apesar destas observações, é considerado como um meio diagnóstico de mastite subclínica, no momento da or- denha, que permite identificar rapidamente o quarto acometido (NMC, 1999).

O WMT resultou do aprimoramento do CMT (NMC, 1999). É realizado em tubos apropriados, que apresentam orifício em suas extremidades, nos quais se colocam quantidades exatas de leite e reagente, que é o mesmo utilizado para o CMT. Este deve ser diluído em água destilada 1:1. Utilizam-se $2 \mathrm{ml}$ deste e $2 \mathrm{ml}$ da amostra do leite. Deve-se proceder a homogeneização com movimentos de rotação do tubo e, a seguir, invertê-lo, mantendo-se por 15 segundos, retornando-se então à posição original do tubo. Quanto maior o conteúdo celular, maior a viscosidade e o volume de mistura que permanece no tubo. A coluna fluida no tubo é medida em milímetros $(\mathrm{mm})$, sendo este teste mais objetivo que o CMT. É empregado em rebanhos maiores e em algumas indústrias de laticínios. Utiliza-se amostra composta dos quatro quartos, o que permite o exame de um maior número de amostras.

A contagem eletrônica de células somáticas no leite é uma forma moderna de diagnóstico de mastite subclínica, aceita internacionalmente como critério de avaliação da sanidade da glândula mamária da vaca e conseqüente qualidade do leite, individualmente por ela produzido, ou pelo rebanho, respectivamente, por exame de amostra do tanque de expansão. Há hoje uma preocupação no estudo dos parâmetros genéticos, de CCS ou do escore de células somáticas (ECS), para incluí-la nos programas de melhoramento genético de bovinos leiteiros (OSTRENSKY, 1999). PHILIPSSON e BERGLUND (1995) concluíram que é possível melhorar a resistência para mastite clínica pela seleção de touros oriundos de fêmeas com baixos níveis de CCS.

Este método é realizado com o auxílio de aparelhos como, por exemplo, o somacount-300 Bentley Instruments Inc. (Figura 3). O aparelho é composto por cinco estruturas, que formam o sistema óptico de leitura, a saber:

1. conjunto de fluidos como o corante brometo de etidium e o de carreamento, que é o detergente RBS;

\section{Computador;}

3. canhão de laser;

4. Leitor, denominado "Flow cell";

5. tubo foto multiplicador, que faz a conversão de impulsos luminosos para impulsos elétricos.

As amostras a serem examinadas, seja individual por quarto, seja composta dos quatro quartos, seja do tanque de expansão, devem ser de cerca de $50 \mathrm{ml}$ de leite, coletados em frascos apropriados, de plástico, contendo como conservante o dicromato de potássio $\left(\mathrm{K}_{2} \mathrm{Cr}_{2} \mathrm{O}_{7}\right)$ 


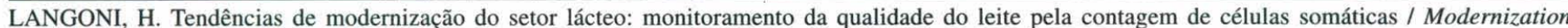

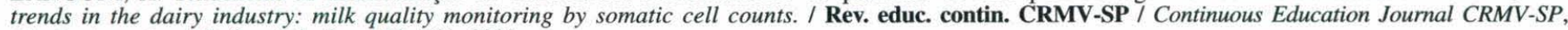
São Paulo, volume 3, fascículo 3, p. 57 - 64, 2000.

ou o bronopol (2-bromo 2-nitro propano - 1, 3diol). Devem ser mantidas em temperatura ambiente e examinadas, no máximo, 5 a 7 dias após a sua obtenção, de acordo com o conservante utilizado. Para o exame de amostra do tanque, deve-se aguardar a ordenha de todos os animais e manter o agitador do tanque ligado por $10 \mathrm{minu}-$ tos para proceder à homogeneização do leite, coletando-se o volume necessário pela parte superior do tanque com o auxílio de uma concha limpa, acondicionando-se no frasco coletor e homogenizando-se com o conservante.

O Núcleo de Pesquisa em Mastites - NU-

Tabela 1. Relação dos resultados do California Mastitis Test com a contagem de células somáticas e a concentração de polimorfonucleares

\begin{tabular}{|c|c|c|}
\hline $\begin{array}{c}\text { Grau de } \\
\text { positividade }\end{array}$ & CCS/mI/leite & Polimorfonucleares \\
\hline Negativo & 0 a 200.000 & $25 \%$ \\
\hline Suspeito & $150.000-400.000$ & $30-40 \%$ \\
\hline+ & $300.000-1.000 .000$ & $40-60 \%$ \\
\hline++ & $700.000-2.000 .000$ & $60-70 \%$ \\
\hline+++ & 2.000 .000 & $70-80 \%$ \\
\hline
\end{tabular}

PEMAS, do Departamento de Higiene Veterinária e Saúde Pública - Faculdade de Medicina Veterinária e Zootecnia da UNESP - Botucatu-SP, está desenvolvendo este tipo de exame, graças ao projeto de pesquisa subvencionado pela Fundação de Amparo à Pesquisa do Estado de São Paulo - FAPESP, que permitiu a aquisição do referido aparelho (Figura 3).

Nesse aparelho, o leite é aspirado (Figura 4), misturado a uma solução, que cora o núcleo das células somáticas. A contagem eletrônica de células somáticas é feita pelo exame de citometria de fluxo, no qual os impulsos luminosos (fluorescentes, sob luz ultravioleta) emitidos pelas células, decorrentes da associação DNAcorante (brometo de etídio), após sua conversão em impulsos elétricos no tubo fotomultiplicador, são lidos pelo aparelho. As células fluorescentes, ao passarem pelo fluxo, carreadas por uma pequena corrente do fluido (RBS), ao serem bombardeadas por um feixe de laser, produzem uma explosão luminosa, de curta refração, que atravessa uma série de filtros ópticos e lentes, sendo focada em um cumprimento de luz apropriado. Esses pulsos de luz são convertidos em pulsos elétricos, amplificados, eletronicamente filtrados e ordenados por tamanho para que se especifiquem as células somáticas. O computador conta os pulsos elétricos, traduzindo a contagem de leucócitos.

A tabela 2 mostra os resultados de escore do CMT, WMT, ECS, CCS, correlacionando-os com as perdas de produção em percentual e estimativas de perdas em $\mathrm{Kg}$ / vaca/ano, segundo PHILPOT e NICKERSON (1992).

\section{Fatores que afetam a CCS}

O principal fator que afeta a CCS em um rebanho ou na vaca leiteira, individualmente, é a presença da infecção ou de inflamação na glândula mamária. No keite de vacas sadias, a CCS é geralmente menor que 200.000 células $/ \mathrm{ml}$ e, às vezes menor que 100.000 células $/ \mathrm{ml}$ nos animais de primeiro parto. Segundo JONES et al. (1984), a partir de 100.000 células/ml, há menor produção de leite e maiores taxas de infecção. De maneira geral, ovvalor de 200.000 células $/ \mathrm{ml}$ é aceito como indicativo da presença de infecção. No Brasil, THIERS et al. (1999) observaram o aumento significativo da CCS na presença

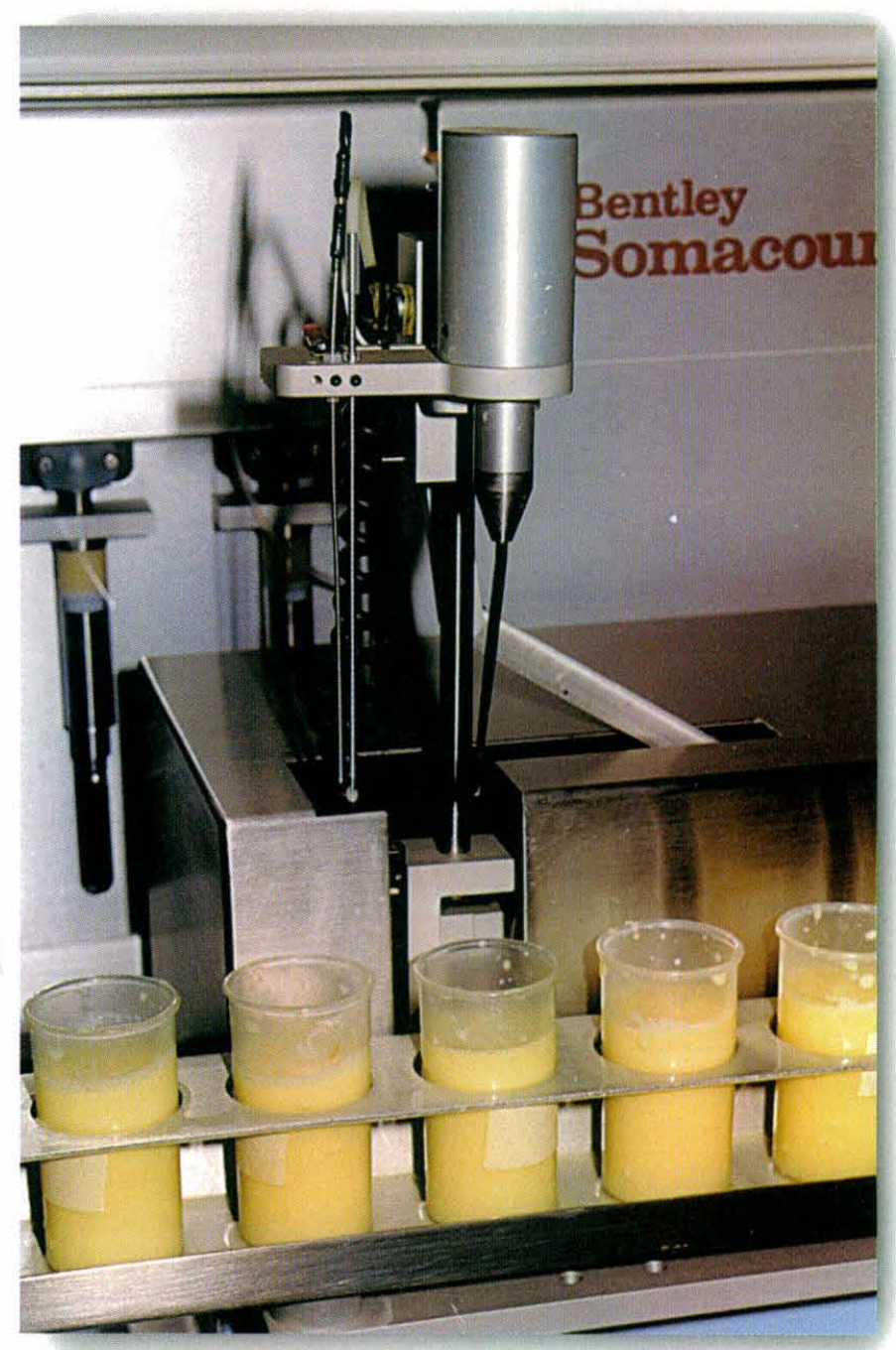

Figura 4. Amostras de leite com conservante para CCS. NUPEMAS, FMVZ, Botucatu, SP. 
LANGONI, H. Tendências de modernização do setor lácteo: monitoramento da qualidade do leite pela contagem de células somáticas / Modernization trends in the dairy industry: milk quality monitoring by somatic cell counts. / Rev. educ. contin. CRMV-SP / Continuous Education Journal CRMV-SP, São Paulo, volume 3, fascículo 3, p. 57 - 64, 2000.

Tabela 2. Relação entre os resultados dos exames de CMT, WMT, CCS e ECS com estimativas de perdas de produção de leite em percentual e em $\mathrm{Kg} / \mathrm{vaca} / \mathrm{ano}$.

\begin{tabular}{|c|c|c|c|c|c|}
\hline $\begin{array}{l}\text { Escore } \\
\text { CMT }\end{array}$ & WMT (mm) & ESC & $\begin{array}{l}\text { CCS } \times 1000 \\
\text { células } / \mathrm{ml}\end{array}$ & $\begin{array}{c}\text { Perdas de } \\
\text { de } \\
\text { Produçáo \% }\end{array}$ & $\begin{array}{l}\text { Estimativas } \\
\text { de perda } \\
\mathrm{Kg} / \mathrm{vaca} / \mathrm{ano}\end{array}$ \\
\hline \multirow[t]{2}{*}{ Negativo } & 2 & 3,0 & 100 & 3 & 180 \\
\hline & 5 & 4,0 & 200 & 6 & 360 \\
\hline \multirow[t]{3}{*}{ Traços } & 8 & 4,6 & 300 & 7 & 450 \\
\hline & 10 & 5,0 & 400 & 8 & 550 \\
\hline & 12 & 5,3 & 500 & 9 & 590 \\
\hline \multirow[t]{5}{*}{1} & 14 & 5,6 & 600 & 10 & 630 \\
\hline & 16 & 5,8 & 700 & & 680 \\
\hline & 18 & 6,0 & 800 & 11 & 725 \\
\hline & 20 & 6,2 & 900 & & 750 \\
\hline & 22 & 6,3 & 1.000 & 12 & 770 \\
\hline 2 & 25 & 6,6 & 1.200 & $>12$ & $>770$ \\
\hline
\end{tabular}

de infecções intramamárias, inclusive para microrganismos tidos como patógenos menores, tal qual o Corynebacterium bovis, sugerindo a necessidade de revisão de conceitos quanto aos aspectos de patogenicidade e de virulência destes.

Situações estressantes de diversas naturezas podem elevar os níveis de CCS em um quarto já infectado. Por outro lado, têm pouco efeito na CCS de vacas não infectadas. Há poucas evidências que qualquer outro fator, com exceção de variação diurna normal, exerça uma influência significativa na CCS, na ausência de infecção intramamária (HARMON, 1998a).

Quanto aos efeitos estacionais, DOHOO e MEEK (1982) referem-se a maiores CCS no verão do que no inverno, levando-se em consideração o aumento de temperatura em umidade relativa do ar. Este fato coincide com um aumento na incidência de mastites clínicas nos meses de verão, o que faz refletir que o estresse térmico não é por si só uma causa no aumento de CCS, mas, sim, resultado de maior exposição das extremidades dos tetos aos microrganismos, favorecendo maior número de novas infecção em casos clínicos durante o verão (HARMON, 1998b)

No que se refere à comparação da coleta das amostras nas diferentes fases da ordenha, NADER FILHO $e t$ al. (1996) realizaram contagens de células somáticas em 65 quartos sadios, durante o início, meio e final da ordenha. Observaram que $100 \%$ das amostras colhidas no início da ordenha apresentaram contagens inferiores a 500.000 céls $/ \mathrm{ml}$, diferentemente das colhidas no meio e final da ordenha, cujas contagens foram superiores ao referido valor em $8(12,3 \%)$ e $19(29,2 \%)$ amostras, respectivamente. Este fato parece assumir importância entre os métodos auxiliares de diagnóstico das formas subclínicas da mastite bovina, que se fundamentam na avaliação do conteúdo celular do leite, uma vez que existe a possibilidade da ocorrência de resultados falsos-positivos, caso as amostras de leite analisadas não sejam colhidas no início da ordenha.

Concluindo-se: não há dúvidas de que o monitoramento da contagem de células somáticas mensalmente, a partir de amostras compostas de leite do animal, ou do tanque, é medida importante para se avaliar a saúde de glândula mamária em um rebanho leiteiro, propiciando a tomada de medidas efetivas para o controle das mastites, permitindo, ainda, uma maior produção de leite de melhor qualidade, melhorando os aspectos de produtividade, tanto para o produtor como para a indústria de laticínios, pela obtenção de maior rendimento na produção dos subprodutos de origem láctea.

Deve-se salientar ainda que programas de controle de mastites fazem reduzir drasticamente a CCS. O plano de cinco pontos do NMC, citado por GOOKIN (1999), que inclui a imersão dos tetos em solução desinfetante após a ordenha, o tratamento antimicrobiano de todos os quartos de todas as vacas no momento da secagem, além do tratamento imediato de todos os casos clínicos de mastites e o descarte de vacas com mastite crônica, é suficiente para reduzir as ta- 
xas de infecções intramamárias e, conseqüentemente, oferecer um leite de melhor qualidade com menor CCS.

No Brasil, METTIFOGO et al. (1999) relataram que, além dessas medidas, a inclusão da redução da utilização de água no preparo dos animais para a ordenha, a revisão e a manutenção de ordenhadeiras, o estabelecimento de ordem de ordenha, iniciando-se com os animais sadios e terminando-se com os acometidos por mastites crônicas, e a adoção de práticas gerais de limpeza e higiene do local de permanência dos animais, reduzem substancialmente a CCS média dos animais de 863.000 para 215.000 células $/ \mathrm{ml}$, em um ano de programa.
Este intento também pode ser alcançado com os programas de pagamento de leite por qualidade, levando-se em consideração o teor de células somáticas, em amostras das propriedades fornecedoras de leite aos diferentes laticínios ou cooperativas de leite. Desta forma, os principais beneficiados seriam os consumidores, que estariam adquirindo e consumindo produtos de melhor qualidade e seguramente livres de microrganismos potencialmente causadores de doenças de caráter zoonótico. Essa prática já vem sendo adotada por algumas empresas, embora de forma tímida, devendo ser a curto prazo incrementada, se realmente desejar-se aumentar a produtividade com a obtenção de leite de melhor qualidade.

\section{SUMMARY}

The dairy industry suffers heavy losses as a result of mastitis, the main infection of dairy cattle. Its multiple etiology makes prophylaxis very difficult. The present study reflects the importance of mastitis control, and discusses aspects of the somatic cell counts in the monitoring of the mammary gland's health, with the objective of obtaining better quality milk, with less infection risks for consumers, because both milk and dairy products can transmit zoonosis agents.

Key words: mastitis, somatic cells, trends, monitoring.

\section{REFERÊNCIAS BIBLIOGRÁFICAS}

1 - BLOOD, D.C.; RADOSTITS, O.M. Clínica veterinária. Rio de Janeiro: Guanabara Koogan, 1991. 1263p.

2 - BRAMLEY, A.S.; CULLOR, J.S.; ERSKINE, R.S.; FOX, L.K.; HARMON, R.J.; HOGAN, J.S.; NICKERSON, S.C.; OLIVER, S.P.; SMITH, K.L.; SORDILLO, L.M. Current concepts of bovine mastitis. Madison: National Mastitis Council, 1996. 64p.

3 - BRASIL. Ministério da Agricultura e do Abastecimento. Portaria n.56 de 7 de dezembro de 1999 . Submete à consulta pública os regulamentos técnicos discriminados, em conformidade aos anexos desta Portaria. Diário Oficial da República Federativa do Brasil, Brasília, n.234, Seção 1, p.34-42, 8 de dezembro de 1999.

4 - COSTA, E.O.; BENITES, N.R.; MELVILLE, P.A.; PARDO, R.B.; RIBEIRO, A.R.; WATANABE, E.T. Estudo etiológico da mastite clínica bovina. Revista Brasileira de Medicina Veterinária, v.17, p.156-8, 1995.

5 - COSTA, E.O.; RIBEIRO, A.R.; WATANABE, E.T.; SILVA, J.A.B.; GARINO JR, F.; BENITES, N.R.; HORIUTI, A.M. Mastite subclínica: prejuízos causados e os custos de pre- venção em propriedades leiteiras. Revista do Napgama, São Paulo, n.2, p.16-20, 1999.

6 - DOHOO, I.R.; MEEK, A. H. Somatic cell counts in bovine milk. Canadian Veterinary Journal, v.23, p.119-25, 1982.

7 - ERSKINE, R.J.; BARTLETT, P.C. Serum concentrations of copper, iron, and zinc during Escherichia coli-induced mastitis. Journal of Dairy Science, v.76, p.408-13, 1993.

8 - GOOKIN, A. Monitoring and controlling mastitis: Progress in Ontario. In: ANNUAL METTING OF NATIONAL MASTITIS COUNCIL, Waterloo 1999. Proceedings. Madison: National Mastitis Council, 1999. p.1-9.

9 - HARMON, R.J. Fatores que afetam as contagens de células somáticas. In: SIMPÓSIO INTERNACIONAL SOBRE A QUALIDADE DO LEITE, Curitiba 1998. Anais. Curitiba: Universidade Federal do Paraná, 1998a, p.7-17.

10 - HARMON, R.J. Physiology of mastitis and factors affecting somatic cell counts. Journal of Dairy Science, v.77, n.7, p.2103-12, 1994. 
LANGONI, H. Tendências de modernização do setor lácteo: monitoramento da qualidade do leite pela contagem de células somáticas / Modernization trends in the dairy industry: milk quality monitoring by somatic cell counts. / Rev. educ. contin. CRMV-SP / Continuous Education Journal CRMV-SP, São Paulo, volume 3, fascículo 3, p. 57 - 64, 2000.

11 - HARMON, R.J. Somatic cell counts: myths vs reality. In: NATIONAL MASTITIS COUNCIL REGIONAL METTING, Madison 1998. Proceedings. Madison: National Mastitis Council, 1998b. p.40-50.

12 - HARMON, R.J., LANGLOIS, B.E. Prevalence of minor pathogens and associated somatic cell counts. In: ANNUAL METTING OF NATIONAL MASTITIS COUNCIL, Bellevine 1986. Proceedings. Madison: National Mastitis Council, 1986. p.11.

13 - JANK, M.S.; FARINHA, E.M.M.Q.; GALAN, V.B. O agribusiness do leite no Brasil. São Paulo: Milkbizz, 1999. $108 \mathrm{p}$.

14 - JONES, G.M.; PEARSON, R.E.; CLABAUGK, G.A. Relationships between somatic cell counts and milk production. Journal of Dairy Science, v.67, n.8, p.1823-31, 1984.

15 - LANGONI, H. Complexidade etiológica da mastite bovina. In: ENCONTRO DE PESQUISADORES EM MASTITES, 3 Botucatu. 1999. Anais. Botucatu: Faculdade de Medicina Veterinária e Zootecnia, 1999. p.3-18.

16 - LANGONI, H.; DOMINGUES, P.F.; SILVA, A.V.; CABRAL, K.G. Aspectos etiológicos na mastite bovina. Revista Brasileira de Medicina Veterinária, v.20, n.5, p.204-10, 1998.

17 - LANGONI, H.; FONSECA, T.H.P. Participação da Listeria monocytogenes na mastite bovina. Importância para a saúde pública. Higiene Alimentar, v.11, n.50, p.36-8, 1997 b.

18 - LANGONI, H.; SALVOLDI, F.; MACHADO, G.S.; CAMARGO, M.J.B. Campylobacter spp. como agente de mastite bovina. Aspectos de saúde pública. Higiene Alimentar, v.11, n.50, p.42-4, 1997a.

19 - LARANJA-DA-FONSECA, L.F. Vamos ser, algum dia, exportadores de leite? Imagem Rural Leite, n.42, p.22-8, 1997.

20 - METTIFOGO, E.; MÜLLER, E.E.; BUZINHANI, M.; YAMAGUTI, M.; SALVADOR, R. Estratégias de controle da mastite bovina utilizando como parâmetro a contagem de células somáticas e o perfil microbiológico. In: ENCONTRO DE PESQUISADORES EM MASTITES, 3, Botucatu 1999. Anais. Botucatu: Faculdade de Medicina Veterinária e Zootecnia, 1999. p.251.

21 - NADER FILHO, A.; AMARAL, L.A.; ROSSI JÚNIOR, O.D.; NASCIF JÚNIOR, I.A. Influência das fases da ordenha sobre o número de células somáticas do leite bovino. In: CONGRESSO BRASILEIRO DE MEDICINA VETERINÁRIA, 24 Goiânia 1996. Anais. Goiânia: Sociedade Brasileira de Medicina Veterinária, 1996. p.121.
22 - NMC. Current concepts of bovine mastitis. Madison: National Mastitis Council, 1996. 64p.

23 - NMC. Laboratory handbook on bovine mastitis. Madison: National Mastitis Council, 1999. 222p.

24 - OSTRENSKY, A. Efeitos do ambiente sobre a contagem de células somáticas no leite de vacas da raça holandesa no Paraná. Curitiba. 1999. 114p. Dissertação (Mestrado) - Setor de Ciências Agrárias. Universidade Federal do Paraná.

25 - OTERO, F.D.; CRUZ, J.R.S. Mecanismos de defesa de la glándula mamaria bovina en las fases de involución y lactación. Veterinaria Mexico, v.23, p.357-65, 1992.

26 - PARANÁ, (Estado), Acompanhamento da situação agropecuária no Paraná. Curitiba: Secretaria do Estado da Agricultura e do Abastecimento, Departamento de Economia Rural. 1999.

27 - PHILIPSSON, J.; RAL, G.; BERGLUND, B. Somatic cell count as a selection criteria for mastitis resistance in dairy cattle. Livestock Production Science, v.41, p.195-200, 1995.

28 - PHILPOT, W.N. Importância da contagem de células somáticas e outros fatores que afetam a qualidade do leite. In: SIMPÓSIO INTERNACIONAL SOBRE QUALIDADE DO LEITE, Curitiba 1998. Anais. Curitiba: Universidade Federal do Paraná, 1998. p.28-35.

29 - PHILPOT, W.N.; NICKERSON, S.C. Mastitis: Counter-attack. Naperville: Babson Bros., 1992. 150p.

30 - PRESCOTT, S.C.; BREED, R.S. The determination of the number of body cells in milk by a method. Journal of Infectious Disease, v.7, p.632, 1910.

31 - RADOSTITS, O.M.; BLOOD, D.C.; GAY, C.C. Veterinary Medicine. London: Bailliere-Tindall, 1994. 173p.

32 - RIBAS, N.P. A hora da CCS. Contagem de células somáticas assegura a qualidade do leite. Produtor Parmalat, n.18, p.26-30, 1998.

33 - SCHALM, O. M.; NOORLANDER, D.D. Experiments and observations leading to development of the California Mastitis Test. Journal of the American Veterinary Medical Association, n.130, p.199-204, 1957.

34 - THIERS F.O.; COSTA, E.O.; GARINO JR, F.; BENITES, N.R. Conteúdo celular do leite de bovinos em diferentes fases da lactação. In: ENCONTRO DE PESQUISADORES EM MASTITES, 3, Botucatu 1999. Anais. Botucatu: Faculdade de Medicina Veterinária e Zootecnia, 1999. p.145.

35 - WATTS, J.L. Etiological agents of bovine mastitis. Veterinary Microbiology, v.16, p.41-6, 1998. 